\title{
La Dama de Elche (La Alcudia, Alicante) y sus contextos arqueológicos*
}

\author{
The Lady of Elche (La Alcudia, Alicante) and her archaeological contexts
}

\author{
Jesús Moratalla Jávega ${ }^{a}$
}

\section{RESUMEN}

Este artículo analiza las huellas de utillaje identificadas en la Dama de Elche, ofreciendo una nueva documentación sobre esta emblemática pieza. Los resultados permiten cuestionar el carácter de busto que tradicionalmente se ha adjudicado a la escultura. En paralelo, se revisa la documentación bibliográfica sobre las circunstancias de su hallazgo en 1897 en el contexto de los descubrimientos posteriores en el territorio ibérico y de las intervenciones arqueológicas en La Alcudia desde 2017. Por último, se propone un recorrido de la escultura desde su función prístina como urna funeraria, pasando por su conversión en busto y su uso final como simple mampuesto de una construcción por definir.

\begin{abstract}
This article analyses the tool traces identified in the Lady of Elche, offering new documentation on this emblematic masterpiece. The results call into question the traditional interpretation that this piece was a bust. We review the existing bibliographic documentation concerning its discovery in 1897 and how this should be revised in the context of later discoveries in the Iberian territory and of the archaeological interventions that have taken place at La Alcudia since 2017. Lastly, we discuss the archaeological journey of the sculpture from its pristine function as a funeral urn, its conver-
\end{abstract}

sion into a bust and its final use as rough stone in a construction yet to be defined.

Palabras clave: Protohistoria; Mediterráneo; escultura ibérica; La Alcudia; damas sedentes; análisis tecnológico; huellas.

Key words: Protohistory; Mediterranean; Iberian sculpture; La Alcudia; sitting ladies; technological analysis; marks.

\section{EL ESTADO DE LAS COSAS}

La Dama de Elche, icono de la arqueología ibérica, seguramente es uno de los objetos arqueológicos españoles más referenciados cien años después de su hallazgo ${ }^{1}$. Por ello parecía fútil un acercamiento estrictamente documental a su estudio. La sensación era que solo quedaba matizar, si acaso, el encuadre estilístico de la escultura y la vía de llegada de la imagen en piedra a la sociedad ibera, asumida como unidireccional.

El ánimo de este texto es plantear nuevas hipótesis sobre las circunstancias del hallazgo de este icono cultural. Su base es la combinación del estudio específico de las variadas huellas de instrumental que presenta la escultura a simple vista con la inferencia que estas proporcionan para el relato de los hechos especialmente de Pedro Ibarra y Ruiz.

Los resultados de las analíticas físico-químicas realizadas a la cavidad trasera que tiene la escultura (Luxán et al. 2011) son el probable detonante de la nueva etapa

\footnotetext{
* Trabajo realizado en el marco del proyecto de investigación PROMETEO/2019/035, LIMOS. "LItoral y MOntañaS en transición: arqueología del cambio social en las comarcas meridionales de la Comunidad Valenciana”, financiado por la Generalitat Valenciana.

a Universidad de Alicante, Dept. de Prehistoria, Arqueología, Historia Antigua, Filología Griega y Latina; Instituto Universitario de Investigación en Arqueología y Patrimonio Histórico (INAPH). Carretera S. Vicente del Raspeig s/n. 03690 S. Vicente del Raspeig. Alicante. Correo e.: jesus.moratalla@ua.es https://orcid.org/0000-0003-0227-6150

${ }^{1}$ El volumen coordinado por R. Olmos y T. Tortosa (1997) sobre la Dama de Elche da una rápida idea del bagaje generado durante el siglo XX. Recibido 26-XI-2020; aceptado 24-II-2021.
} de uso y distribución "Creative Commons Reconocimiento 4.0 Internacional” (CC BY 4.0) 


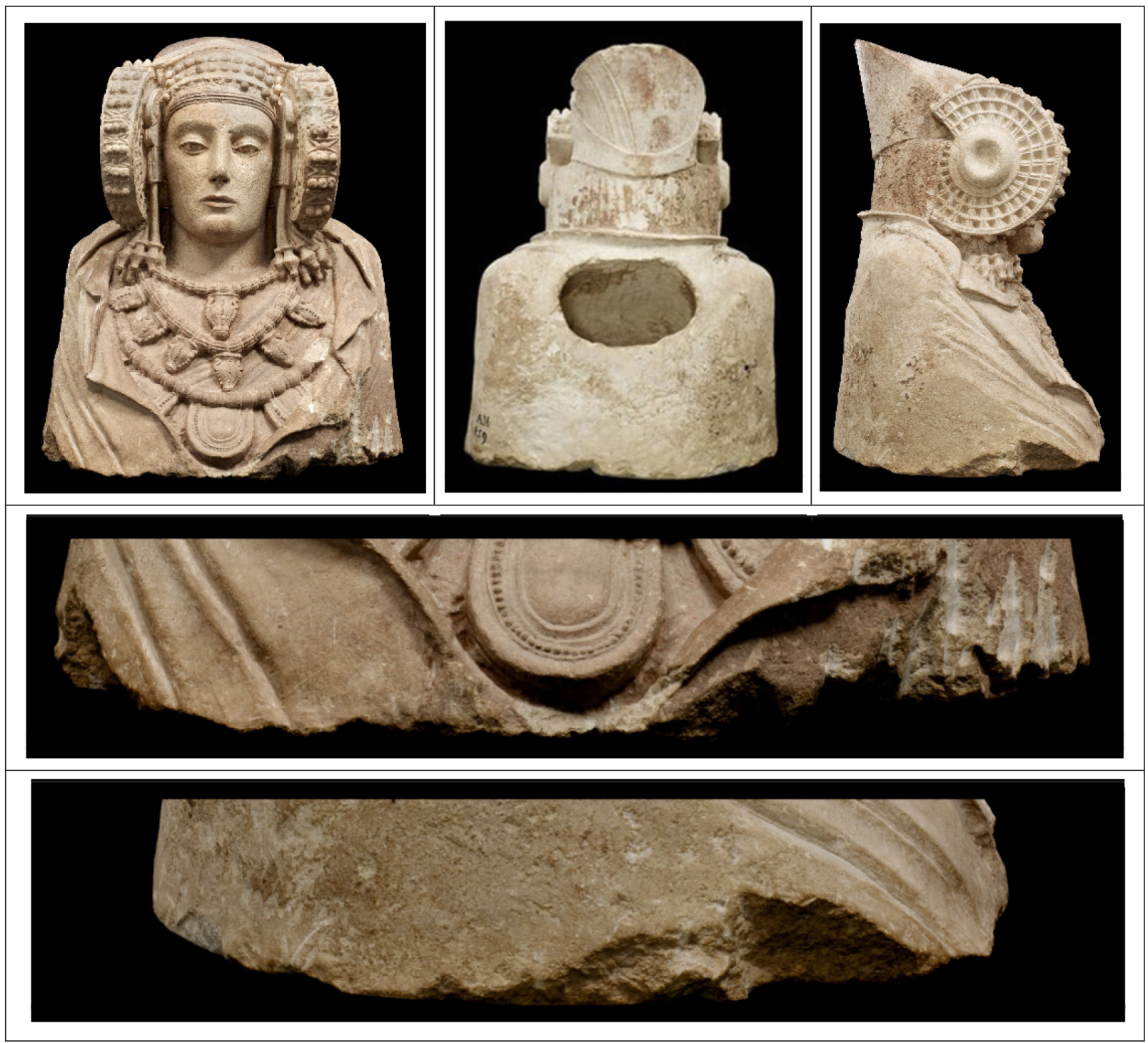

Fig. 1. Dama de Elche: frente, espalda y costado derecho (Museo Arqueológico Nacional, Inv. 1971/10/1, Foto. Fundación ITMA. Autor Santiago Relanzón). Debajo, detalles de la rotura de manto y pliegues causados por el corte irregular y también del fuerte golpe lateral. En color en la edición electrónica.

de investigación ${ }^{2}$, como prueba la producción bibliográfica (Gutiérrez Lloret 2017; Aranegui 2018; Ronda 2018a, 2018b; Albert-Llorca et al. 2018). Los resultados confirmaban, con pocas dudas ${ }^{3}$, su uso como continen-

M. Bendala (1994, 1995) introdujo novedades en la interpretación de la escultura que comentaremos más adelante.

La cavidad podría ser posterior al diseño original, lo que daría otra función a la escultura. Sin embargo, en la estupenda fotografía en 3D alojada en el servidor del Museo Arqueológico Nacional (MAN) el bloque de roca caliza presenta un lustre homogéneo sin una discontinuidad cromática entre la superficie de la concavidad y la del resto de la escultura que sugiera su abertura posterior. Merecería la pena abordar esta cuestión con nuevos análisis sobre la Dama. te de restos humanos incinerados-cremados (Fig. 1) y, por tanto, su conceptualización como urna cineraria. Su determinación funcional puso fin a un debate iniciado prácticamente desde su descubrimiento con la idea de Th. Reinach (1858-1932) de que era un objeto funerario, permitiendo su incorporación a coordenadas espaciotemporales plenamente ibéricas (Fig. 2).

Determinada con cierta precisión su función primigenia, los estudios de los últimos años han atendido en especial a las circunstancias de su hallazgo en La Alcudia de Elche. Para este tema es imprescindible la revisión documental de A. Ronda (2018a) a la que nos remitimos. El relato, publicado en Elche. Materiales para 


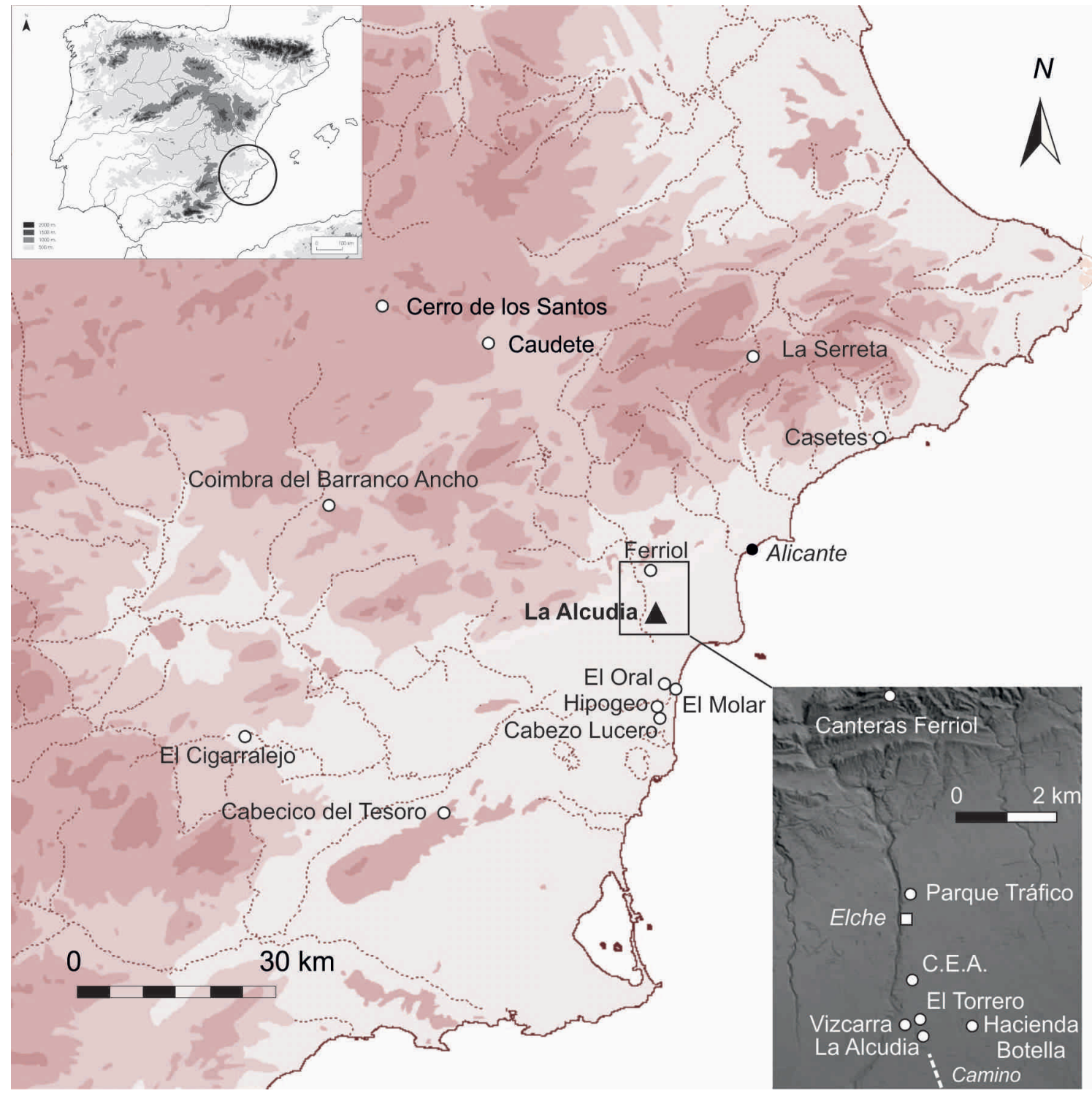

Fig. 2. Localización de La Alcudia de Elche (Alicante) en el sudeste de la península ibérica y de los yacimientos ibéricos citados en el texto, detallando en la parte inferior los del entorno de La Alcudia. Base cartográfica: mapa superior cortesía I. Grau, mapa inferior fuente: elaboración propia a partir de Mapa Base Topogràfic de la Comunitat Valenciana; mapa de sombras de $1 \mathrm{~m}$ de resolución obtenido a partir del vuelo LIDAR de 2009 C Institut Cartogràfic Valencià https://visor.gva.es/visor/ (consulta 2-03-2020).

su historia por P. Ibarra $(1926)^{4}$, archivero del cabildo ilicitano en el momento del hallazgo y primer relator de su contexto arqueológico, discordaba del de Ramos

${ }^{4}$ Esta obra es la versión final de una investigación al menos con dos manuscritos preliminares, más extensos, depositados en el Museo Arqueológico-Histórico de Elche. El identificado como b-325 de diciembre de 1919 solo recoge el apartado arqueológico del libro. El b-326 de 1922 debe ser el manuscrito que presenta Ibarra en 1923 al ayuntamiento de Elche para su impresión. Incluye unos apéndices sobre Edad Media y más dibujos. El libro, publicado finalmente en Cuenca, refleja este último manuscrito, pero sin los magníficos dibujos de Ibarra.
Folqués (1944). Según Ibarra, "el busto" había aparecido "aislado y rodeado de tierra compacta, mezclado con cenizas y avecindado con piedras de construcción de igual naturaleza que la de los trozos de pared que vi que derrocaban los operarios, al día siguiente del hallazgo; muchísimos tiestos ibéricos y no pocos huesos humanos y otros que me parecieron de ave"s.

\footnotetext{
5 El texto amplía la escueta descripción de Ibarra (1926: 195). Corresponde a una carta dirigida a E. Hübner (mayo de 1898), recogida en el manuscrito b-325 de 1919 (véase n. 4). En otra carta a J.R. Mélida (13 de
} 
Según A. Ramos Folqués que sigue el relato de Manuel Campello, supuesto autor material del hallazgo casi cincuenta años antes, la imagen apareció de manera casual cuando picaba con una cuadrilla de obreros en el margen oriental del altozano de La Alcudia, al socaire de unos trabajos agrícolas. La escultura apareció por sorpresa "en posición normal, un poco inclinada sobre la derecha, la cara hacia el sudeste, en dirección a Santa Pola. Se encontraba sobre dos losas de piedra trabajada, cubierta de tierra, que se desprendía fácilmente de la cara y del pecho, la espalda y sus costados estaban protegidos por otras losas similares a las que servían de base; había seis, dos detrás y dos en cada lado" (Ramos Folqués 1944: 6) ${ }^{6}$. Acompañaba la descripción un célebre esbozo del propio A. Ramos, luego recreado (Fig. 3). En él se percibía con claridad el diseño de un contexto arqueológico donde la escultura tenía un relevante papel en el momento de ser depositada en el terreno. Estaba de pie en una especie de hornacina y, por tanto, mantenien-

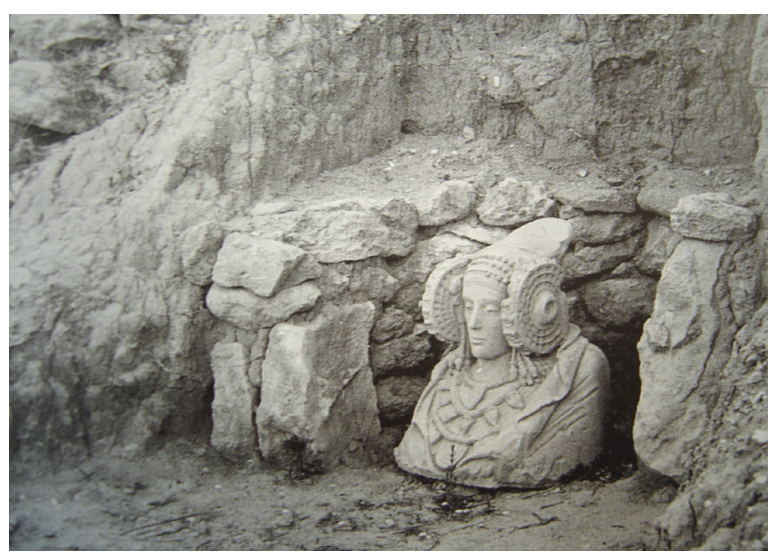

Fig. 3. Recreación del hallazgo de la Dama según la historiografía tradicional (Ramos Fernández 2003; fig. 26, p. 109, fotografía Ramos Folqués, Archivo Fundación Universitaria La Alcudia de Investigación Arqueológica).

do en gran medida su carácter simbólico primigenio.

Las diferencias de relato son obvias. Ibarra localizaba la escultura entre un estrato que hoy identificaríamos claramente en cualquier excavación como un horizonte de vertidos y/o escombros de todo tipo, generado a partir de distintos procesos postdeposicionales. Allí la pieza ya habría perdido por completo su valor prístino. De acuerdo con A. Ramos, la Dama ha-

octubre de 1897), en la página 378 del mismo manuscrito, concreta más la cerámica que identificó en el lugar del hallazgo: "barro negro del género italogriego; barro blanco decorado con pinturas rojizas, ornamentales, de carácter ibérico y más propiamente saguntino".

${ }^{6}$ Sorprende la precisión de la descripción, dado que Manuel Campello, según parece, era analfabeto y de lengua valenciana. bía mantenido su carácter de icono funerario-religioso. Por ello, había sido cuidadosamente escondida y protegida -coincidiendo, según él, con la presencia bárquida entre la comunidad ibera, es decir, en el siglo III a. C.-Habría permanecido hasta el momento mismo de su hallazgo en un contexto arqueológico muy determinado, manteniendo así su halo poco menos que mágico.

$\mathrm{Ni}$ que decir tiene que esta segunda hipótesis fue finalmente la asumida. A su mayor "atractivo" coadyuvaron, a nuestro juicio, dos factores. P. Ibarra había fallecido en 1934 y su obra, publicada casi veinte años antes del artículo de A. Ramos, había tenido escasa difusión. El segundo factor fue la completa asunción del relato de A. Ramos por parte de la comunidad científica del momento. No nos consta que se levantara voz alguna que discrepara de dicha hipótesis, transmitida, recordemos, sin ningún tipo de evidencia gráfica.

Nosotros mismos (Albert-Llorca et al. 2018) hemos puesto en duda este último relato. Nuevos documentos arqueológicos anulan -a nuestro juicio- cualquier posibilidad de que la Dama hubiera aparecido de pie y, como derivada, el relato sobre las condiciones precisas de su hallazgo en posición vertical. Ello revaloriza la narración de P. Ibarra. El documento en cuestión es la presencia de tres surcos perfectamente distinguibles, cerca de la base de la escultura, hacia su parte izquierda. Dichos surcos se deben a golpes de pico -dado su característico perfil en $\mathrm{V}-$, cortos y menos profundos los dos primeros, más largo -de unos $8 \mathrm{~cm}-\mathrm{y}$ profundo el tercero (Fig. 4).

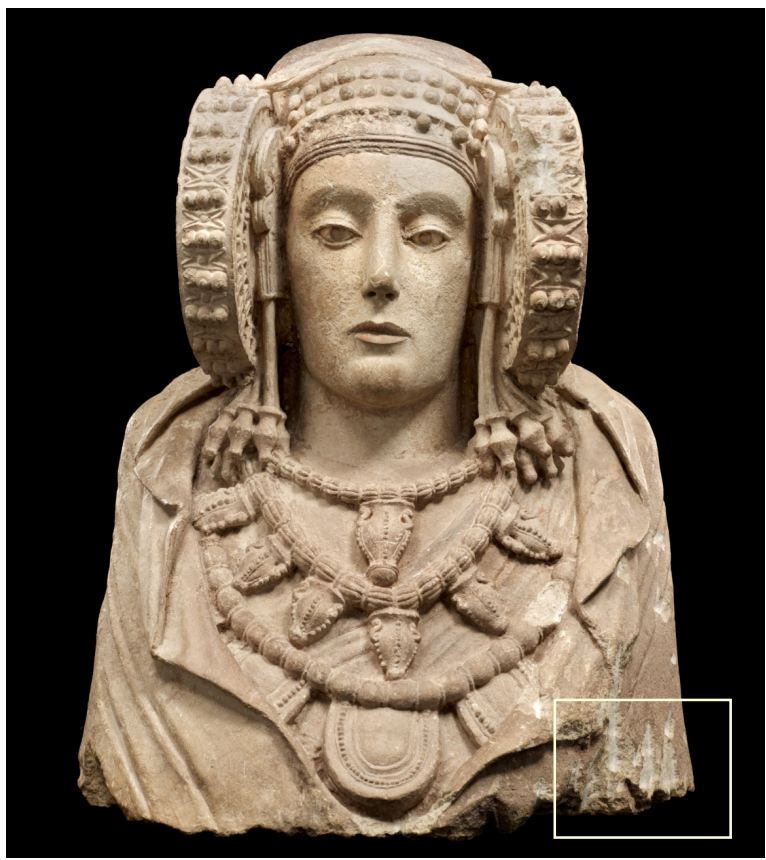

Fig. 4. Dama de Elche frontal, marcando en recuadro la zona afectada por los golpes de pico. Museo Arqueológico Nacional. Inv. 1971/10/1 (fotografía Fundación ITMA, autor Santiago Relanzón). En color en la edición electrónica. 
La coloración blanquecina resultante del impacto en la superficie de la escultura confirma que se produjeron en el momento de su localización. Las fracturas antiguas muestran otra pátina $\mathrm{y}$, además, los surcos ya aparecen claramente en las primeras fotografías de Ibarra (Fig. $5)^{7}$.Es imposible, por tanto, que, si la escultura hubiera estado de pie, el pico alcanzara su base sin afectar antes la cabeza o los rodetes, por no hablar de las losas que supuestamente la rodeaban. Sólo una cava muy forzada, anatómicamente hablando, y absurda desde el punto de vista del trabajo en curso en el margen del bancal, podría justificar que el pico alcanzara la base -con un golpe que superaría los casi $60 \mathrm{~cm}$ de altura de la escultura- sin haberla descubierto antes. Obviamente damos por hecho que una vez identificada la extracción fue más cuidadosa. Compartimos con otras autoras (Aranegui 2018: 94; Ronda 2018b: n. 34) la hipótesis de que la Dama

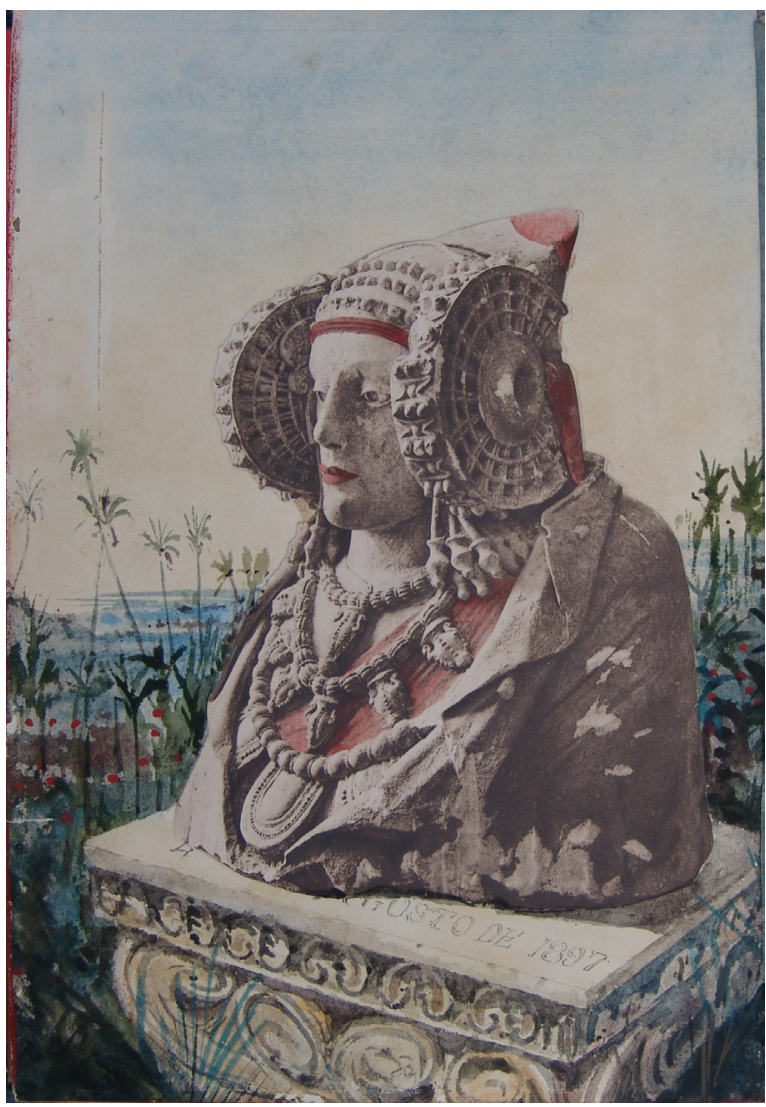

Fig. 5. Dama de Elche pintada sobre fotografía (fotografía P. Ibarra. Archivo Museo Arqueológico-Histórico Elche). En color en la edición electrónica.

El mismo costado presenta otras pérdidas menores, posiblemente originadas también en la extracción de 1897. Estas huellas conviven con otras roturas antiguas, como la que recubre con una oscura pátina la zona afectada del rodete izquierdo. de Elche, cuando apareció, estaba acostada, boca arriba y posiblemente algo levantada por el costado izquierdo que recibió los golpes.

Es difícil imaginar qué pudo ser de la escultura en el segmento histórico entre su uso como urna funeraria ibérica y su reutilización en una hipotética construcción desconocida, relacionada de algún modo con estratos de vertidos de tierra superficiales. En las líneas que siguen propondremos distintas posibilidades sobre estos episodios de la vida de la Dama. Asumimos desde el principio que hay distintos contextos arqueológicos para la pieza, valorada de varias maneras por las culturas que le dieron vidas sucesivas. A efectos antropológicos, ha llegado casi hasta nuestros días (Albert-Llorca y Rouillard 2020).

\section{LA URNA}

La constatación fehaciente de que la oquedad trasera de la escultura sirvió como contenedor de cenizas y huesos humanos ${ }^{8}$ sitúa la efigie en un paisaje funerario que resta por descubrir. Su uso la aleja por completo de conjuntos escultóricos con los que se la suele emparentar, como los de Cerro de los Santos (Ruiz Bremón 1989; León 1998; Chapa y González 2013) o Porcuna (Blanco 1987, 1988a, 1988b; Negueruela 1990; Chapa et al. 2009) ${ }^{9}$, y la acerca inevitablemente a esculturas halladas en necrópolis como el guerrero y la Dama de Baza (Presedo 1982; Chapa e Izquierdo 2010). El paralelismo funcional con la segunda se antoja contundente, por más que la oquedad no esté exactamente en su espalda. A nuestro parecer, la Dama de Elche fue una obra escultórica, sin duda sobresaliente, que contuvo como urna los restos incinerados de un personaje suponemos ilustre de la sociedad ibera del momento. Proponemos su depósito en un hipogeo funerario que la salvaguardó durante un tiempo prolongado.

Los hipogeos o fosas funerarias en la Contestania ibérica son mucho menos comunes que en el área andaluza, siempre como definición de un estatus aristocrático (Pereira 1987: 268-269; Ruiz et al. 1992). Planteamos su presencia en el levante a partir de tres indicios. Una es la fosa no menor de la tumba 17 de Casetes, en Villajoyosa (García Gandía 2003), datada hacia 600 a. C. que acoge los restos de una mujer. Hay noticias

\footnotetext{
8 El hueco tiene $18 \mathrm{~cm}$ de diámetro por $16 \mathrm{~cm}$ de profundidad (Ramos Fernández 2008); aunque obviamente no es una perfecta semiesfera, el espacio resulta más que suficiente para contener los restos de la cremación de una persona adulta, o parte de los mismos. La oquedad labrada en el trono de la Dama de Baza resulta mayor, pues es un rectángulo de 17 x 16 x $22 \mathrm{~cm}$ (Presedo 1973: 190), como también el hueco que ofrece el llamado Busto del Parque de Elche (Ramos Molina 2000: 45-46).

9 No valoraremos las cuestiones de estilo, perceptibles entre los conjuntos citados y la Dama, especialmente cercanos con el probable heroon de Porcuna.
} 
de un posible hipogeo en la cercana necrópolis de El Molar (Senent 1930: 3; Peña 2003: 29, fig. 5) ${ }^{10}$, prácticamente para las mismas fechas en las que debió labrarse la Dama. El tercero es el hipogeo con acceso escalonado hallado al pie mismo de Cabezo Lucero (Mas 2017). Cuenta con una necrópolis de época plena con estatuaria sobradamente conocida en la bibliografía ibérica (Aranegui et al. 1993). No es una pauta funeraria extraña en la Contestania, de ahí que propongamos como hipótesis que el destino inicial de la Dama de Elche fuera una tumba de cámara subterránea, grosso modo, como la recreación propuesta para el hipogeo de la Dama de Baza (Chapa e Izquierdo 2010: 30, fig. 2). La singularidad del contenedor radica en la excepcional calidad de la escultura. Nos parece obvio que debió albergar los restos de una persona detentadora del máximo rango social, sea cual fuera su naturaleza, entre la comunidad ibera.

En resumen, el contexto arqueológico original de la escultura fue probablemente una tumba, realizada hacia mediados del siglo V a. C. ${ }^{11}$ y ubicada no lejos del altozano de La Alcudia. El hallazgo en su zona liminal complica su localización precisa. Se ha propuesto que la propia eminencia alojara una necrópolis ibérica (Tendero2016; Aranegui 2018: 34), si bien, al no haberse documentado nunca incineraciones en años de excavaciones en La Alcudia ${ }^{12}$, parece razonable situar el ámbito de los muertos en sus alrededores. La localización concreta de la escultura en el cuadrante suroriental del yacimiento anima a situar el camposanto hacia esta vertiente. Allí pudo situarse una entrada principal del asentamiento ibérico (Moratalla 2015: 83), pero tal hipótesis carece de base empírica. Las noticias sobre tumbas de incineración (Fig. 6) sitúan la necrópolis, o al menos una de ellas ${ }^{13}$, en la parte opuesta del yacimiento, hacia el noroeste (Lorenzo de San Román 2014: 101 y 104) ${ }^{14}$. Tampoco resulta determi-

\footnotetext{
${ }^{10}$ De la necrópolis del poblado de El Oral (Abad y Sala 2001) situada a unos $15 \mathrm{~km}$ al sur de La Alcudia, proceden al menos dos esculturas de animales (Llobregat 1972).

${ }^{11}$ Los trabajos de P. León (1998) o L. Abad (2014) proporcionan los argumentos estilísticos para tal datación.

${ }^{12}$ La tesis de A. Ronda (2018b) es ya un documento imprescindible para el conocimiento de la arqueología ibérica de La Alcudia. Nosotros mismos (Moratalla 2004-2005) planteamos una hipótesis sobre su secuencia evolutiva que mantenemos.

${ }^{13}$ Como mínimo una segunda se localizaría en Hacienda Botella (Guardiola 2001), a escasos $800 \mathrm{~m}$ al nordeste de La Alcudia.

${ }^{14}$ En la necrópolis del Torrero se hallaron en el siglo XIX urnas con restos incinerados e inhumaciones plenamente romanas. Las incineraciones se han adscrito al periodo altoimperial romano, pero nada impide suponer que sean más antiguas. La situación aproximada de dicha necrópolis dista del altozano de La Alcudia apenas $100 \mathrm{~m}$ al noroeste y del huerto de Vizcarra unos $200 \mathrm{~m}$ al este. Allí apareció a principios del siglo XIX, entre otras piezas, la conocida dama de Vizcarra (Llobregat 1972: 151152, fig. 90). Además, está a $800 \mathrm{~m}$ al sur del Campo de Experimentación Agrícola donde también se cita el hallazgo de urnas de incineración.
}

nante el lugar de localización de la pieza en el siglo XIX, pues fragmentos de escultura ibérica aparecen por todo el asentamiento (Ramos y Ramos 2004). La última hipótesis, a día de hoy difícil de contrastar, es que hubiera otro tipo de paisaje sacro definido por una sola tumba de incineración.

El diseño y factura de la Dama partió muy probablemente de la iniciativa de una comunidad local claramente jerarquizada cuya estructura socio-política vestía los ropajes estilísticos llegados desde Focea. Cualesquiera que fueran los mecanismos de esta transmisión ${ }^{15}$ dio a luz un prototipo canónico de la belleza ibérica, tan híbrida a la vez, de raíz orientalizante, pulcra en su modelado, inexpresiva en su apariencia. Para ello, extrajeron la piedra caliza de las sierras septentrionales ilicitanas, especialmente de la de Ferriol (Rouillard et al.2020), de canteras situadas escasamente a un par de horas de camino a pie desde La Alcudia. Allí eligieron el o los bloques ${ }^{16}$ a labrar, que seguramente ya esbozaron en la propia cantera. Más tarde en el asentamiento, la obra fue completada en un taller. Esta logística productiva se compadece mejor con una organización del trabajo propiamente local que con la llegada de ímpetus foráneos: la Dama es producto, se nos antoja, de una ya dilatada experiencia artística de origen local.

\section{EL BUSTO}

La idea de que la Dama se concibió como un busto arranca desde su descubrimiento. Así la llamaba P. Ibarra y así la consideró la comunidad científica con franca naturalidad, aunque tal definición la convirtiera prácticamente en unicum en la estatuaria ibérica (Ruano 1987: I, 332-333 y 475bis-476) ${ }^{17}$. Que nos conste, M. Bendala (1994, 1995: 300) es quien primero sostiene el carácter estante de la obra "tal vez se decidió dar forma de busto a la estatua originaria”. Antes A. Blanco Freijeiro (1960: 115-116) defendió que la escultura de la Dama de Elche estaba cortada y en origen era proba-

15 Estamos con C. Aranegui (2011-12: 427) en que la sociedad ibérica conoció una notable expansión griega de origen masaliota hacia los siglos V-IV a. C. y en ella hemos de buscar el vehículo de transmisión que deparó una obra como la Dama. Determinar exactamente qué mano trabajó el bloque de piedra resulta muy difícil de concretar, pero cabe recordar ejemplares de la estatuaria ibérica ilicitana, como el torso de guerrero con el kardiophylas pectoral delicadamente labrado con la testuz de un lobo, para contextualizar la pieza en un conjunto artístico amplio y variado. No se trata de una obra aislada, sino más bien del producto de un taller con impronta propia (León 1998; Chapa y Belén 2011).

16 Sobre si en origen fue un busto reflexionamos más adelante.

${ }^{17}$ La obra de E. Ruano (1987) da una idea de la singularidad de los bustos en la estatuaria ibérica. De un total cercano a los 500 fragmentos escultóricos, sólo 19 (3,8\% del total) se adscriben a esa categoría (16 femeninos y 3 masculinos), a veces con la posibilidad de que correspondieran a esculturas estantes o sedentes. 
blemente sedente y con función funeraria, una idea que seguiría F. Presedo (1973: 193) emparentándola con la de Baza. La novedad de los trabajos de M. Bendala es su nueva base empírica arqueológica, su lectura de las huellas de instrumental que presenta la escultura que va más allá de una apreciación visual. Ofrece otra visión de la escultura al mostrar su base de apoyo, donde son claramente perceptibles las marcas en negativo de un útil. Retomamos ahora esta imagen (Fig. 6), donde se percibe un conjunto de huellas, ejecutadas con pre-

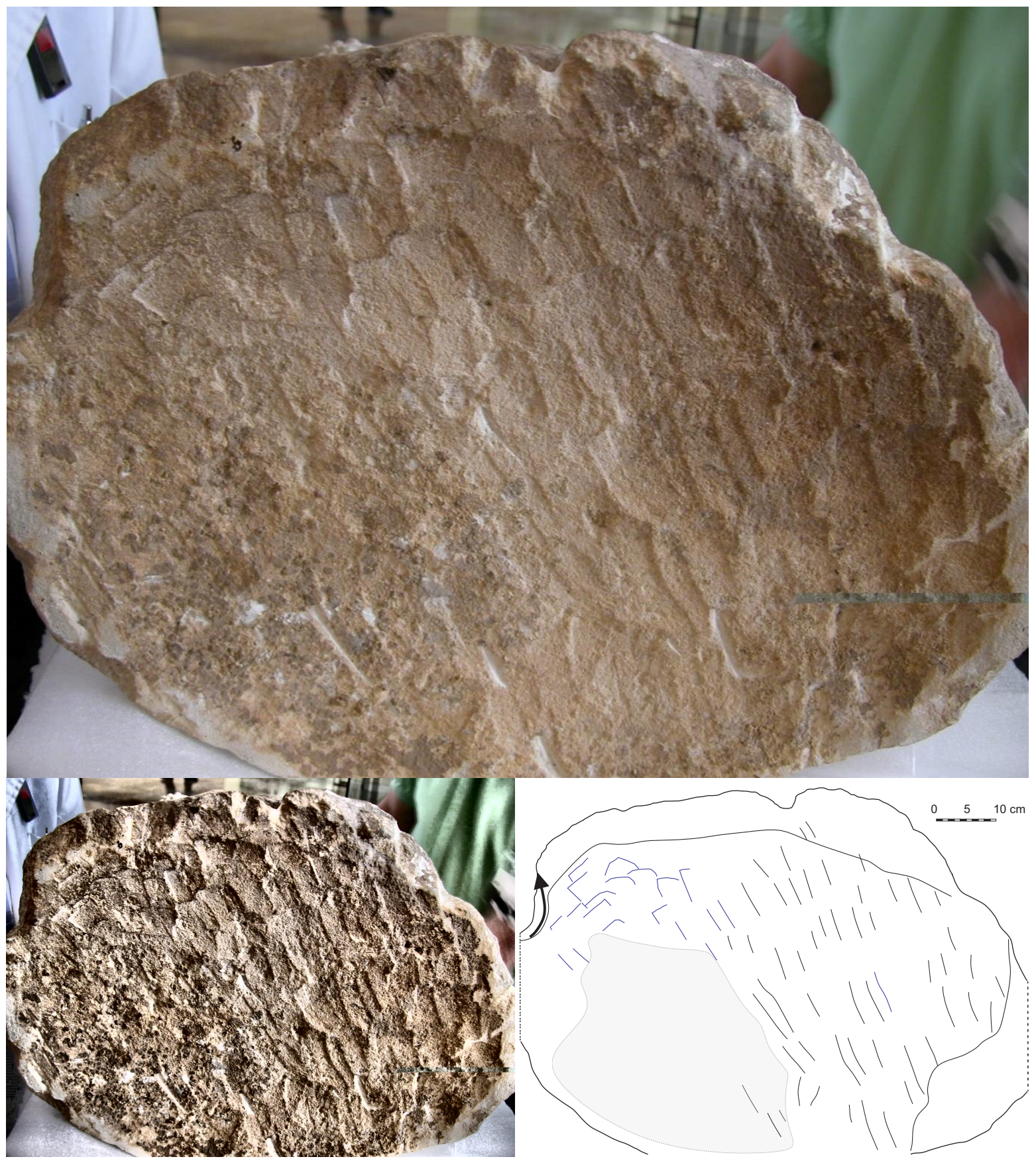

Fig. 6. Dama de Elche (Museo Arqueológico Nacional). Imagen ecualizada de la base (cortesía P. Rouillard). Dibujo de las huellas percibidas, marcando en tono gris suave la zona donde estas no aparecen. La flecha indica el plano de rotura con el golpe lateral de la escultura. En color en la edición electrónica.

Trab. Prehist., 78, N..$^{\circ}$, julio-diciembre 2021, pp. 366-380, ISSN: 0082-5638 https://doi.org/10.3989/tp.2021.12282 
cisión siguiendo una dirección prefijada que requiere una mínima habilidad y oficio. La búsqueda consciente de un acabado horizontal concreto suele ser habitual en la talla escultórica ibérica (Negueruela 1990-91; Blánquez y Roldán 1994), aunque, como igualmente recuerdan I. Negueruela (1992: 24) y Bendala (1995, 300), la Dama carecería de basa propiamente dicha.

La imagen de la superficie de asiento y del dibujo que trazan en ella las sucesivas marcas del instrumental empleado permiten inferir cuestiones de interés, cuya confirmación requiere una detenida revisión visual directa de la base que no hemos realizado. Se ha propuesto que una alcotana produjera el corte de la base (Ramos Fernández 1996-97: 140), algo que ahora podemos completar a partir del estudio del utillaje empleado en las canteras históricas de Ferriol (Rouillard et al. 2020). Con diferencia, el taillant o marteau taillant $^{18}$ fue uno de los útiles más empleados en la extracción de los bloques. Similar a un hacha, pero con doble filo simétrico, su golpeo genera un surco de unos $6-6,5 \mathrm{~cm}$ de anchura, levemente curvado en arco y con una superficie con lustre, como se observa en la Dama $^{19}$. Fue muy utilizado para alisar las caras de los bloques extraídos en las canteras que suponemos ibéricas (Rouillard et al. 2020: 72, fig. 57a), y creemos que también se empleó en este caso.

Las mediciones que presentamos se deducen de las fotografías consultadas y de la escala que proporcionan las medidas del busto $(56 \times 45 \times 37 \mathrm{~cm})$, por lo que admitimos que pueda haber un mínimo error en las mismas. El surco que hemos podido medir en la Dama ronda los $5 \mathrm{~cm}$ de longitud, excesivo para una alcotana. Es más probable que lo produjera un útil similar a un hacha, como el trinchante referido, o una versión menor con mango más corto. La corroboración de esta hipótesis requeriría un examen directo de la escultura.

La direccionalidad de las huellas y su superposición -muy legible en el remate de la labra de la base en el cuadrante superior izquierdo- sugieren que los golpes se realizaron muy probablemente con la escultura tumbada bocarriba y girada sobre su costado izquierdo. Las huellas se desarrollan de derecha a izquierda, según la perspectiva de la figura 9, superponiéndose al final del recorrido. Se disponen en abanico pasando de $75^{\circ}$ en los primeros surcos a $140^{\circ}$ en los últimos. Interesa reseñar que carece de huellas la porción de la

\footnotetext{
${ }^{18}$ La palabra no existe en lengua castellana, siendo la escoda o trinchante el instrumento más parecido, si acaso de un tamaño menor. Como no podemos confirmar que se trate del mismo útil, mantenemos el original en francés.

${ }^{19} \mathrm{Mi}$ más sincero agradecimiento a C. Blondeau, directora del Musée archéologique du Val d'Oise y autora del estudio de las marcas de útiles documentadas en las canteras de Ferriol, por las apreciaciones realizadas sobre el tipo de útil que pudo dejar las marcas en negativo documentadas en la Dama.
}

base situada en el cuadrante inferior izquierdo, de la que parten las huellas de corte. Nos parece que esta circunstancia sugiere que la escultura ya estaba fracturada antes de emplear el instrumental cortante y por eso más tarde fue innecesario regularizar esta zona. La zona coincide con un gran golpe, antiguo, en el costado derecho de la Dama (Fig. 9). El desbaste de la base que hoy conocemos tomó la línea de fractura como superficie de referencia para su nivelación. La presencia o ausencia de huellas en la base invita a pensar, en definitiva, que la efigie original nunca fuera un busto.

Como ya remarcó M. Bendala (1995: 300, 2006: 53) la afección de las huellas sobre los pliegues del manto que porta la Dama inclina a defender su posición original sedente o estante. La línea de fractura de la base de la escultura rompe claramente los pliegues y el manto en varios puntos (Fig. 9). El corte, en general bastante irregular y desportillado, apenas pasa por debajo del medallón central del gran collar. Resulta inconcebible que el bloque de piedra se cortara para realizar un busto cuando la escultura estaba ya labrada y pulida. Esa línea marcada por el corte no era su remate original, ergo no se concibió como busto. Con ello no negamos que existiera este formato escultórico en el arte ibero. Ciertamente lo parecen el guerrero de Baza (Chapa y Olmos 1999) o incluso el hallado en el Parque de Tráfico de Elche, también de uso funerario (Ramos y Ramos 1992; Chapa y Belén 2011: 167). Más controvertida resulta la Dama de Cabezo Lucero. Llobregat y Jodin (1990: 115) ya en esta primera edición mencionan sin mostrarlo un fragmento de escultura que ratificaría, "con cierta licencia", su carácter de busto al mostrar una especie de plinto que supondría un límite claro para la escultura. Tampoco la exposición de la pieza en el MARQ lo ha recuperado (Olcina 2007). Tras revisarlo en este museo nos parece poco probable que se corresponda con el referido plinto. Por encima de la supuesta base plana -una pestaña lisa de apenas $1 \mathrm{~cm}$ de longitud- se proyecta una pared claramente cóncava, en paralelo a la superficie de apoyo, dibujando a su vez un contorno curvado. La morfología no es la esperable para una pequeña basa. Se acerca más bien a otra parte de la escultura, tal vez la zona del cuello y el contacto con un rodete. No dudamos del carácter funerario de la Dama de Cabezo Lucero, dado su contexto de aparición, pero no creemos bien argumentado que este fragmento sea un busto, un busto que, al asemejarse tanto a la propia Dama de Elche, genera entre ambas piezas un discurso circular, una es un busto porque la otra lo es....

Consideramos que el busto de la Dama de Elche resulta de una reparación de la figura, reparación con sus propias implicaciones simbólicos, y que, en origen, habría sido concebida como una urna funeraria con forma de dama posiblemente sedente (Blánquez y Comas- 
Mata 1999). La llamada Dama de la Adormidera sería un paralelo en la propia Alcudia (Ramos Molina 2000: 35-36). No descartamos por completo que pudiera tener formato estante, aunque los paralelos conocidos son siempre de dama sedente. M. Albert y P. Rouillard (2020: 36) han hecho ver que, en la espalda de la Dama de Elche, ningún elemento recuerda a un trono, lo que apoyaría su carácter estante. Tampoco olvidamos que hay ejemplos sedentes donde nada delata que hubiera un trono. El cuerpo se asienta mejor sobre un sillón de brazo como el del Cigarralejo (Cuadrado 1995), o sin ellos, como el de la Dama de Caudete (Ruano 1987: III, 108-110; Truszkowski 2003: 318-319; Ramos Fernández 2008: fig. 9), o los de varios ejemplares del Cerro de los Santos (Ruano 1987: I, 261-272) donde tienen un volumen notablemente inferior.

En resumen, la Dama de Elche es el resultado de la redefinición de su formato original, quebrado por circunstancias desconocidas, para que mantuviera su magnificencia inicial. El mantenimiento de su alto valor simbólico sólo se explica si todo el proceso se enmarca dentro de la propia sociedad ibera. Según nuestra hipótesis la escultura, depositada en un hipogeo funerario desde mediados del siglo $\mathrm{V}$ a. C., fue parcialmente rota en una acción difícil de precisar. El golpe del costado derecho, sin huellas de útil, parece una fractura natural causada por una caída accidental, ligada a una acción violenta, o incluso a un temblor sísmico de una tierra tan dada a ellos. El episodio hemos de situarlo en las coordenadas históricas propiamente iberas, pues la pieza fue "revivida" en un acto religioso propio de la sociedad que la creó. Entronca así, inevitablemente, con la posibilidad planteada desde hace décadas (Tarradell 1968) de que dicho grupo social hubiera conocido movimientos iconoclastas, posiblemente de carácter dinástico, que hubieran afectado a la imaginería ibérica (Chapa 1993). Muy claro parece este episodio violento en Porcuna (Chapa y Zofío 2005), donde las caras de los protagonistas del monumento escultórico han sido machacadas con saña. Muy cerca en la necrópolis de Cabezo Lucero (Rouillard 1986: 342; Aranegui et al. 1993: 73) la escultura aparece bien machacada, reutilizada en tumbas del siglo IV a. C. avanzado. En cambio, la figura de la Dama eludió este destino: fue recuperada como busto, quizás depositada en su mismo contenedor funerario, y allí debió quedar alojada hasta el punto donde fue hallada en 1897, su último contexto arqueológico.

\section{LA PIEDRA}

La escultura ibérica es ampliamente reutilizada en la arquitectura posterior al asentamiento ibérico, en especial en las primeras estructuras romanas, pero no sólo en ellas (Ramos y Ramos 2004). Ya A. Ramos Folqués (1955), en sus excavaciones, menciona una calle romana pavimentada, en parte, con fragmentos de escultura ibérica (el pectoral lobuno, la segunda dama, la cabeza de grifo...). No son raros los hallados en las excavaciones más recientes como en el tramo excavado de la muralla occidental o en el espacio termal inmediato a las llamadas "Casas ibéricas" (Tendero et al.2014: 233-234, fig. 6; Ronda 2018b: 173, fig. 205), ambos contextos de transición al cambio de era. Es decir, en época romana la escultura ibérica fue un simple mampuesto, troceado y levemente escuadrado si era necesario, para levantar construcciones relativamente sólidas. De objeto de culto había pasado a simple piedra, que además debía de ser fácil de aprovisionar, dado el notable número de hallazgos en estas circunstancias. Por ello, insistimos, su depósito original no debía andar lejos del altozano, o incluso puede que algunas estuvieran en la propia elevación, si admitimos que los programas escultóricos que desarrollan algunos fragmentos, como la escena de lucha recreada por C. Aranegui (2018: fig. 30), pudieron pertenecer mejor a ámbitos sacros (Corzo 2014: 33).

Se ha propuesto el hallazgo de la escultura en 1897 en este contexto de reutilización (Aranegui 2018; Ronda 2018a). La Dama habría corrido la misma suerte que las esculturas contemporáneas, si bien cada autora ha introducido matices en su interpretación de ese contexto arqueológico, como veremos. El excelente estado de conservación de la pieza, comparado con los de las otras, hace dudar que la escultura sufriera el mismo fin que sus coetáneas: en nuestra opinión, ello añadiría un argumento a la idea de que su evolución contextual fue probablemente única.

Una vez superado el episodio historiográfico que situaba su hallazgo casual de pie y en una hornacina, C. Aranegui (2018: 94, fig. 46) ha propuesto que la pieza fuera un simple mampuesto en la fortificación romana de la colonia. A. Ronda propone el mismo fin, retomando el relato de P. Ibarra (1926: 205) sobre su aparición "en el emplazamiento de las murallas de Illici". Añade que el bloque fue convenientemente protegido al situarlo en el aparejo de la obra, en el interior de la muralla, como si de algún modo se intentara mantener su carácter sacro (Ronda 2018a:301). Sin ser absolutamente descartable su localización en una muralla -más adelante expondremos las dudas que la idea nos genera-, incidimos ahora en los argumentos, poco convincentes, sobre el carácter ritual de esta acción.

Se arguye que el destino de la Dama de Elche pudo parecerse al que tuvo el cuerpo de una leona reutilizada como mampuesto en un supuesto tramo de la muralla 
oriental del yacimiento alcuditano ${ }^{20}$, presumiblemente de época ibero-púnica (Ramos Folqués 1955). La escultura habría aparecido "guarecida por un nicho de piedras que se situó en la base de la muralla en época de Augusto" (Ronda 2018a: 301, fig. 18). Merece la pena comentar los tres documentos fotográficos de la época en los que se ve dicha pieza, aportados para apoyar el argumento (Fig. 7). En la primera foto se percibe el hallazgo a distancia, en una zanja de unos $2 \mathrm{~m}$ de anchura realizada al pie del talud de un bancal de similar altura. En su punto intermedio se ve un gran agujero, que ha afectado al perfil del talud a modo de ventana. En su base está el torso de piedra de la leona ya parcialmente descubierto. La segunda es un primer plano de la figura, completamente excavada, situada dentro de un círculo de tierra y junto a la "ventana" del perfil, y con un guijarro bajo su pata trasera izquierda. En la tercera el torso está rodeado y cubierto en parte por un círculo de piedras de tamaño pequeño y mediano. Las fotografías, en especial la tercera, no sostienen en lo más mínimo la veracidad arqueológica del relato. Por ningún lado aparece una evidencia nítida de la fortificación que pudiera contener la figura. A lo sumo en la segunda fotografía se perciben una serie de posibles suelos de cantos en la pared del perfil. Más bien lo que se observa es una concavidad sobre el terreno arenoso del yacimiento donde parece estar alojada la escultura. No se ve el relleno de piedras donde debía estar embutido el bloque esculpido, que está liberado de cualquier material que lo cubriera o rodeara en la segunda fotografía. Por último, la disposición de las piedras que lo rodean en la tercera fotografía proyecta tantas sombras

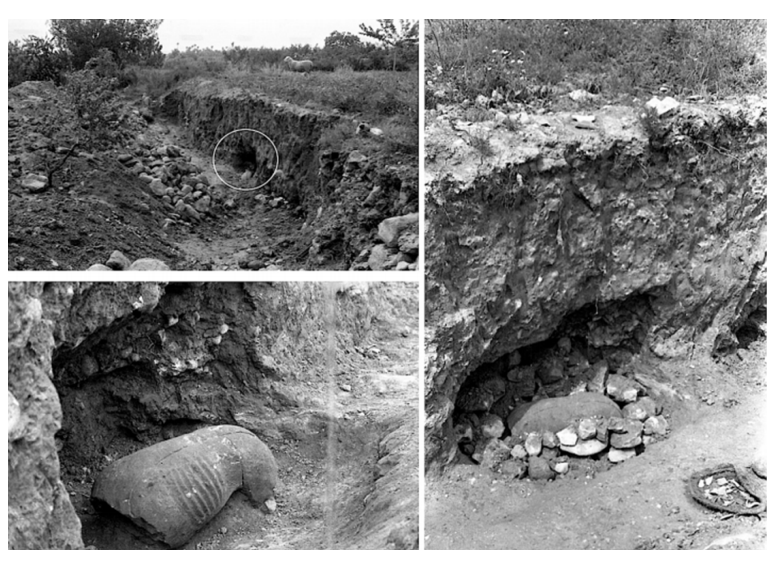

Fig. 7. Fotomontaje del hallazgo de la leona ibérica (Ronda 2018: fig. 18).

${ }^{20}$ La descripción de A. Ramos Folqués (1955: 112) es tremendamente ambigua: la escultura fue hallada "En el interior de esta supuesta muralla y a metro y medio de ella y en una depresión del terreno encontramos el torso de una leona..." que resulta bastante difícil de admitir que acaban de ser excavadas. Estas piedras no aparecen en la segunda fotografía. En nuestra opinión, dicha fotografía es una escenificación posterior al hallazgo de la leona, luego el argumento no es adecuado para defender el carácter sacro de su última deposición, sin entrar en que sigue sin percibirse su reutilización en una fortificación. El argumento, claro está, vale para la Dama.

La idea de C. Aranegui (2018: 94) de que el bloque hubiera sido reutilizado como simple mampuesto en una muralla de piedra, ya convinimos que no debe ser una hipótesis por completo rechazable. Sin embargo, un par de factores nos ofrecen algunas dudas. Uno procede de la propia obra de Ibarra y el otro de las excavaciones en curso en la zona desde $2017^{21}$ (Fig. 8).

Es conveniente recordar que el relato de P. Ibarra se basa en su visita al lugar al día siguiente del descubrimiento del busto, luego la fisonomía del terreno no debía haber cambiado demasiado. Ibarra siempre escribe que la Dama apareció como un bloque aislado, junto a otros materiales arqueológicos propios de una zona de vertidos (cerámicas, tierra compacta, cenizas, huesos, fauna, restos constructivos de paredes...). Su descripción no da pie a pensar que allí hubiera restos de una fortificación. Precisamente que remarcara el carácter aislado de la pieza apoya el argumento contrario, esto es, no había más bloques parecidos a la Dama ni lejanamente. Nos parece improbable que Ibarra (1926: 205) no viera la muralla que el día anterior había alojado la escultura. Su referencia a su hallazgo "en el emplazamiento de la muralla de Illici" hay que entenderla como una suposición de la zona donde estaría la fortificación. Ni la describió nunca ni mucho menos la situó en su plano. Él era un investigador meticuloso, que ya había demostrado sus capacidades en 1890 con la excavación del hypocaustum de las Termas Occidentales de La Alcudia. Envió su memoria escrita a la Real Academia de la Historia con planos e incluso alguna fotografía de la intervención ${ }^{22}$. También dibujó a tinta de modo exhaustivo lo que él interpretó como muralla occidental del asentamiento ${ }^{23}$, luego no era lego en la materia y debía

\footnotetext{
${ }^{21}$ Desde este año la Universidad de Alicante inició tres proyectos arqueológicos en La Alcudia. J. Uroz, el primer investigador principal (IP) del denominado "Damas y Héroes. Tras la Ilici ibérica", centró la excavación en la zona donde se enclava el templete conmemorativo del hallazgo. Hoy A. Lorrio dirige el proyecto. Un segundo proyecto se localiza en las llamadas Termas Orientales de La Alcudia, con J. Molina como IP. El tercero "Domus. Vivir en Ilici", cuya IP es S. Gutiérrez Lloret y en el que participa quien esto suscribe se centra en el sector 4F.

${ }^{22} \mathrm{Su}$ fotografía del hypocaustum de las termas debe ser la primera o de las primeras imágenes de una excavación arqueológica en sentido estricto en tierras alicantinas.

${ }^{23}$ Buena parte del trazado por él descrito pertenece a la fachada occidental del edificio termal flavio (Abad et al. 2000), pero ello no le incapacita para identificar una obra antigua y subrayar sus caracteres principales.
} 


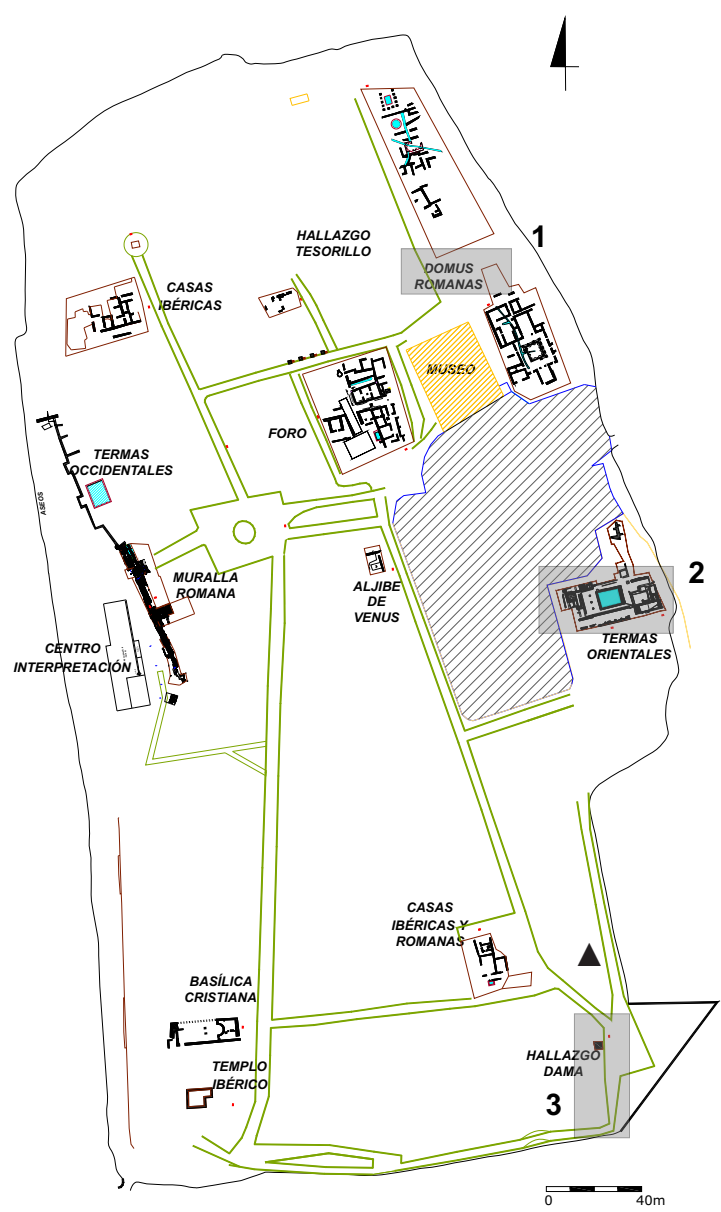

Fig. 8. Plano de La Alcudia con indicación de los sectores intervenidos por los proyectos: 1. Domus, 2. Astero y 3. Damas y Héroes. El triángulo marca el lugar de hallazgo de la Dama de Elche según el plano de P. Ibarra, reproducido por A. Ronda (2018: fig. 4). Planimetría Archivo Fundación Universitaria La Alcudia de Investigación Arqueológica (2003). En color en la edición electrónica.

tener muy habituado el ojo para identificar restos antiguos en una loma que visitaba asiduamente. Además, en $1897^{24}$ excava un cuadro inicialmente situado a 60 $\mathrm{m}$ del punto del hallazgo, localizando 19 inhumaciones en fosas revestidas de cal y canto. Una de ellas con dos inhumaciones, se había quedado apenas a " $4 \mathrm{mt}$ [cuatro metros] al Norte" del lugar donde se halló el busto ${ }^{25}$. De nuevo, obvia cualquier referencia a la exhumación

\footnotetext{
${ }^{24}$ En el manuscrito de 1922 la efeméride 126 refiere el 8 de octubre de 1897 el hallazgo de dos sepulturas en La Alcudia relacionadas con esta intervención (Ibarra 1922: 261). En el libro (Ibarra 1926: 155) concreta que la excavación se desarrolló ese año entre el 6 de agosto y el 8 de octubre.

${ }_{25}$ Página 380, manuscrito b-325 de diciembre de 1919, previo a la publicación de Ibarra (1926), depositado en el Museo ArqueológicoHistórico de Elche (véase n. 4).
}

de muralla alguna, localizando, además de las sepulturas, estratos de tierras revueltas de todo tipo, como los que ya había descrito para la Dama. Insistimos, pues, en la gran importancia del relato de Ibarra para valorar el contexto arqueológico final de aparición de la Dama.

El segundo factor que nos hacen poner en duda la reutilización de la escultura como mampuesto de una muralla deriva de los primeros resultados alcanzados por el proyecto de intervención arqueológica emprendido en el área aproximada donde se localizó la Dama $^{26}$. Allí apareció un primer paisaje arqueológico definido por tumbas de inhumación de época, como poco, tardorromana, a veces perforando suelos de opus caementicium. El paisaje recuerda bastante al localizado en su día por P. Ibarra, a saber, un horizonte arqueológico de tumbas tardías. Es decir, en el nivel superior de la zona hay una necrópolis, por lo que no podemos descartar que esta misma área funeraria fuera la intervenida en el momento mismo del hallazgo de la Dama. De hecho, los materiales muebles que se citan entonces se compadecen bien con este horizonte de inhumaciones entre capas de rellenos variados o sobre suelos de obra de estancias romanas.

Bajo este horizonte se han publicado imágenes de una notable fortificación a una cierta profundidad, muy bien delineada. Sus excavadores la sitúan, preliminarmente, en una fase preaugustea. La muralla se define a partir de un zócalo de mampostería de doble paramento y relleno de bloques y tierra, sobre el cual se dispone un cuerpo de adobes. Quedamos a la espera de la oportuna publicación de estos interesantes restos para valorar hasta qué punto pudo ser reutilizada la Dama en el relleno de esta fortificación.

Ni el relato de Ibarra, ni el de A. Ramos Folqués, vinculados al hallazgo de la escultura, refieren una excepcional cava para alcanzar la pieza. Según el primero, los nuevos bancales que por entonces se delineaban tenían una elevación "de metro y medio" ${ }^{27}$, lo que nos permitiría interpretar la sección reconstruida, sin escala, que A. Ramos Folqués (1944: fig. 2, II) publica por el punto de hallazgo de la Dama. Según esta y la escala que proporciona la altura del terraplén, la escultura habría sido hallada a $30-40 \mathrm{~cm}$ de profundidad. Por ello, se nos antoja que la línea de muralla ahora localizada tal vez está demasiado profunda para que hubiera sido alcanzada al realizarse el bancal. Es más

\footnotetext{
${ }^{26}$ La información sobre esta excavación procede de la propia web de difusión sobre Actualidad Universitaria de la Universidad de Alicante: https://web.ua.es/es/actualidad-universitaria/2018/mayo18/14-20/ una-investigacion-de-la-universidad-de-alicante-podria-haber-sacadoa-la-luz-el-contexto-de-ocultacion-de-la-dama-de-elche.html (consulta 9-7-2021).

27 Página 383, efeméride n. ${ }^{\circ} 149$ (24 de agosto de 1898), manuscrito b-325 de diciembre de 1919, previo a la publicación de Ibarra (1926), depositado en el Museo Arqueológico-Histórico de Elche (véase n. 4).
} 
razonable suponer que, en el momento del hallazgo, los terrenos afectados serían los propios del horizonte superior, donde se localizaban las inhumaciones. El nivel es muy similar al documentado en la excavación de la muralla occidental del asentamiento. Allí son numerosos los estratos y procesos postdeposicionales que llegan a la interfaz de la muralla conservada (Tendero et al. 2014: 238). Por lo general están poco compactados $\mathrm{y}$ tienen abundante material y obliteraban la fortificación desde hacía mucho tiempo.

A fines del siglo XIX la finca de La Alcudia conoce distintos procesos de transformación agrícola, que han podido desfigurar por completo la estratigrafía arqueológica de determinados puntos de la misma. El propio Ibarra habla de ellos en sus escritos ${ }^{28}$. Hemos de esperar a la publicación de resultados para seguir reflexionando sobre las consecuencias de las nuevas intervenciones en la definición del contexto arqueológico secundario de aparición de la escultura.

Proponemos ahora otras opciones que conjugan el relato de los hechos, los trabajos agrícolas entonces en curso y el estado de conservación de la Dama. Este, en grado casi óptimo, permite descartar que la pieza hubiera estado en algún momento a la intemperie. Desde el instante en el que se extrajo de su depósito original -supongamos el hipogeo ibérico- hasta su colocación donde fue hallada, debió pasar un corto lapso de tiempo. Debió ser un traslado rápido e inmediato a la toma de decisión. Su incorporación al macizado de una muralla es una hipótesis a considerar, y justificaría su buen estado de conservación al haber sido protegida por otros mampuestos. Ya hemos expuesto ciertas discrepancias que pudieran poner en duda tal afirmación y nos invitan a ampliar las perspectivas interpretativas. El horizonte arqueológico que excava Ibarra poco después, junto al lugar del hallazgo de la Dama, define con casi total seguridad un área funeraria de época tardorromana-visigoda (Lorenzo de San Román 2014) ${ }^{29}$. Este horizonte se generaliza en muchos puntos de La Alcudia cuando esta va abandonando su urbanismo romano. Surgen distintas áreas donde se disponen tumbas de inhumación, a veces de cierta envergadura, que también reaprovecharán elementos de piedra trabajada de época ibérica (Ronda 2018b: 216, fig. 281). Sugerimos que la pieza pudo ser recuperada, en un contexto difícil de precisar, en época tardorromana y fue situada prontamente en un lugar donde quedó a cobijo. Pudo ser una fortificación, pero también pudo

\footnotetext{
${ }_{28}$ Por ejemplo, página 356, efeméride de 4 de julio de 1889 , manuscrito b-325 de diciembre de 1919, previo a la publicación de Ibarra (1926), depositado en el Museo Arqueológico-Histórico de Elche (véase n. 4).

${ }^{29}$ Incluso su referencia a huesos que le parecen de ave podría esconder realmente el hallazgo de restos de inhumaciones infantiles.
}

ser reutilizada en una construcción, en una tumba de cierta monumentalidad..., siempre carente de todo su valor simbólico. Quienes efectuaron su último traslado lo desconocerían por completo.

\section{CONCLUSIONES}

El recorrido realizado en páginas atrás por los contextos arqueológicos donde pudo yacer la Dama de Elche hasta el momento de su hallazgo transcurre por un sendero donde se entrecruzan los datos ciertos, las hipótesis posibilistas y las conjeturas más o menos razonables. Este recorrido se resume en su función prístina como urna funeraria, su conversión en busto y su uso final como simple mampuesto de una construcción por definir.

La Dama de Elche se labró en origen con un fin funerario, entroncando con creaciones similares del mundo ibérico como las damas de Baza, del Cigarralejo, de Cabezo Lucero y, posiblemente también, de Caudete, Benimassot (Cortell et al. 1989) o Cabecico del Tesoro $^{30}$ y del propio yacimiento de La Alcudia, como la Dama de la Adormidera y seguramente la de Vizcarra. Forma parte de un conjunto de esculturas de morfología similar muy difundidas entre los Iberos. Su mensaje religioso-funerario era compartido por una amplia comunidad local, siendo uno de los principios ideológicos fundamentales que definen la cultura ibérica. La elección de la figura esculpida es una cuestión mayor y debe vincularse con la estructura del poder local. La genial labra de la Dama de Elche va en la misma dirección, alcanzando las más altas cotas de calidad artística de la estatuaria ibérica, irrepetible. Se eligió una imagen icónica de una mujer lujosamente vestida, tal vez la divinidad principal del panteón local. Si atendemos lo que es norma en las lecturas iconográficas del mundo clásico, acompañaría hacia el más allá a un personaje de sexo desconocido, sin duda de posición relevante en la sociedad.

La forma y emplazamiento de la tumba es desconocida. Los paralelos referidos, excepto el de Cabezo Lucero por incompleto, proponen el modelo de figura femenina sedente, que sería la primera opción. No descartamos por completo su carácter estante. El modelo existe en ámbitos sacros $\mathrm{y}$, como han señalado M. Albert y P. Rouillard, (2020: 36) nada hay por su espalda que insinúe un trono, como sería esperable. El contenedor tuvo que ser grande, siendo la tumba de Baza el ejemplo paradigmático de dónde pudo situarse la Dama. Por ello se ha propuesto que hubiera estado

\footnotetext{
${ }^{30}$ Existe un amplio debate sobre la feminidad de esta escultura fragmentaria y sobre la pieza de Vizcarra (Ruiz Bremón 1991).
} 
contenida en un hipogeo, cuya fábrica no era desconocida para las comunidades iberas de la zona. Esto es coherente con el excelente estado de conservación de la escultura, que no parece en ningún caso haber sido expuesta al aire libre.

Su situación es otro ejercicio de especulación. Según los datos disponibles, no hay más tumbas en el altozano alcuditano que varias inhumaciones infantiles, por lo que habría que suponer que se encontrarían en su entorno inmediato. La distancia no sería excesiva, pues la densidad de hallazgos escultóricos en la loma es relativamente alta, sugiriendo que el lugar se convirtió en cantera de piedra una vez dejó atrás su función como necrópolis ibérica. Hay $800 \mathrm{~m}$ en línea recta hasta el área de Hacienda Botella. Este yacimiento acoge algunas incineraciones sencillas en urnas de orejetas, un fragmento escultórico de felino ${ }^{31} \mathrm{y}$ un excepcional ustrinum del siglo III a. C., luego en este radio podría encontrarse cualquier otro ámbito funerario. La vieja referencia de Vizcarra y el hallazgo antiguo de urnas de incineración ${ }^{32}$ apuntan hacia el cuadrante noroccidental del altozano. Tampoco es descartable que hubiera otra necrópolis hacia el sudeste, cerca de donde apareció la Dama y en el entorno del encuentro de la loma con el camino prerromano que por aquí se sigue, tal vez indicando una puerta principal de acceso al asentamiento. El paisaje sería el propio de los grandes oppi$d a$ del entorno, como Verdolay, Cigarralejo, Coimbra del Barranco Ancho o La Serreta, esta en el siglo III a. C. (Moratalla 2016). En este espacio relativamente reducido y bastante densificado se combinan el ámbito residencial, el funerario y el sacro ${ }^{33}$.

En un momento indeterminado dentro del tiempo ibero, se repara la figura original, alterada por causas desconocida a juzgar por la huella del instrumental constatado sobre la base y el frontal de la escultura en especial en su borde inferior. El hallazgo de la Dama de Torres ayuda a imaginar cómo pudo ser el proceso. La escultura (Bandera y Molina 2002: lám. 1) apareció partida en dos, con una línea de fractura oblicua, pero se mantuvo íntegra. Es posible imaginar que una fractura similar hubiera afectado a la Dama y, por lo

31 G. Lara Vives, G. 2016: El proceso de adopción de los modelos itálicos. La topografía de la Colonia Iulia Ilici Augusta como ejemplo. Tesis doctoral inédita, Universidad de Alicante. Alicante, I, pp. 258-262.

32 En una intervención arqueológica dirigida por el autor hace unos años en el camino del Borrocat, inmediatamente al este de La Alcudia, se descubrió lo que parece la necrópolis romana altoimperial de la colonia (en estudio). Las tumbas son de inhumación datables desde el siglo I d. C. Por eso, suponemos que las incineraciones citadas son ibéricas, como opina G. Lara (nota 30, I, 254).

${ }^{33}$ La estructura territorial del poblamiento ibérico en La Alcudia y su entorno (Rouillard et al. 2020: 84) parece dibujar aureolas concéntricas alrededor del altozano con distintos fines en su ocupación: un primer radio de aproximadamente $1 \mathrm{~km}$ acogería los indicios funerarios, a partir del cual se distribuirían los ámbitos productivos. que sea, se descartara la parte inferior y se retocara en forma de busto el fragmento superior, recuperándolo para su función probablemente original, tal vez en forma de herma (Reinach 1898: n. 1). Ello podría explicar la concavidad en la base del busto. El ejemplo valdría tanto para una escultura estante como sedente, a la vista de los bloques que componen la Dama del Cigarralejo.

Para el contexto del hallazgo damos por cierto que la pieza, o mejor el bloque, fue reutilizada en algún tipo de construcción que la dejó oculta, en posición tumbada, boca arriba y levemente alzada en su lado izquierdo, muy probablemente cubierta por piedras y tierra. Ello garantizó su sensacional estado de conservación. A partir de aquí volvemos a entrar en el terreno de las interpretaciones más o menos posibilistas.

La Dama de Elche no siguió el proceso del resto de hallazgos escultóricos ibéricos, en su casi totalidad mutilados y reutilizados en construcciones posteriores $\mathrm{y}$, en especial, en las primeras construcciones romanas. Cuando la colonia inicia su recorrido histórico, la escultura ibérica era un simple mampuesto, recogido por los alrededores. Parece razonable pensar por ello que, dado el estado de conservación de la escultura, la Dama no era visible entonces, oculta quizás en su hipogeo original, en vez de suponer que la escultura generó una pauta conservadora de carácter sacro distinta a la del resto de esculturas a las que acompañaba. Conviene recordar que la Dama de la Adormidera apareció en un altísimo grado de fragmentación en contextos secundarios de época romana, como el enlosado de una posible calle. La hipótesis del autor plantea, pues, su emplazamiento posiblemente en su lugar original hasta el mismo momento de su reutilización.

¿Cuándo se produjo esta? Volvemos a la conjetura. La efigie no muestra efecto alguno de una larga exposición al aire libre, por lo que debió ser "descubierta" en un contexto histórico desconocido y transportada casi de inmediato a su nuevo depósito. Podría ser una buena opción una muralla de la ciudad: recientemente se ha descubierto un lienzo de una fortificación en el flanco suroriental de La Alcudia. No obstante, allí la muralla aparece a una cierta profundidad y, en su momento, se alcanzó la Dama sin excavar en exceso. Además, la loma conoció en el siglo XIX profundos cambios en su fisonomía. En dicho cuadrante los niveles superiores se relacionan con tumbas de inhumación, datables a partir de época tardorromana, algunas abiertas en el horizonte de opus caementicium. El proyecto iniciado en 2017 las ha documentado, como también P. Ibarra 120 años antes. La duda queda ahí: si la acción del 4 de agosto de 1897 superó este nivel de tumbas alcanzando una posible línea de fortificación, o si por el contrario nunca se alcanzó dicho horizonte constructivo. Entonces la Dama pudo estar alojada en alguna construcción funeraria de este nivel 
tardío. Al menos una tumba tardorromana reutilizaba una escultura ibérica de más de $35 \mathrm{~cm}$ de longitud (Fig. 9) en su cubierta (Ronda 2018b: 216). Podría ser una hipótesis a considerar en el futuro, pues no dudamos que se seguirá escribiendo largo y tendido sobre una obra de arte ibérica sencillamente apasionante.

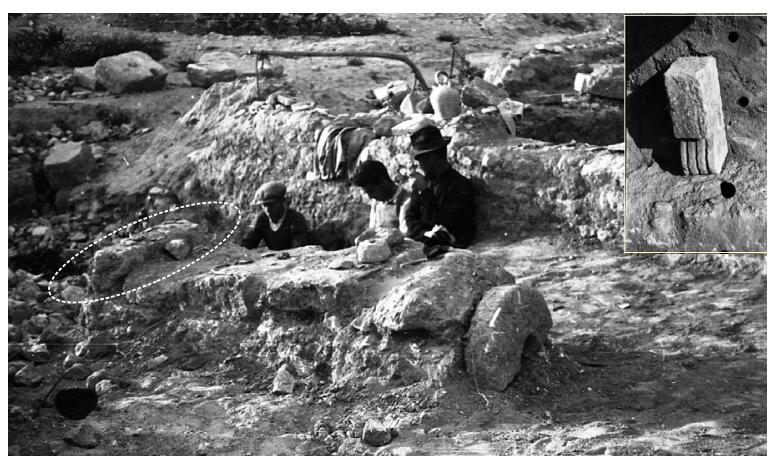

Fig. 9. La Alcudia. Fotomontaje de una tumba tardía excavada en 1953. En la imagen principal se perciben los bloques dispuestos sobre la tumba, cuya cabecera debe ser el fragmento de estatuaria ibérica hallado en el conjunto, tal vez el brazo de un sillón, que reproducimos arriba a la derecha (fotografías 023-1953-ARF-negativos 445 y 023-1953-ARF-negativos 528, Fondo Alejandro Ramos Folqués).

\section{BIBLIOGRAFÍA}

Abad Casal, L. 2014: "De nuevo sobre la Dama de Elche. Apuntes para una reflexión”. En P. Bádenas, P. Cabrera, M. Moreno, A. Ruiz; C. Sánchez y T. Tortosa (eds.): Homenaje a Ricardo Olmos. Per speculum in aenigmate. Miradas sobre la Antigüedad. Estudios y textos de Erytheia 7, Asociación Cultura Hispano-Helénica. Madrid: 315-319.

Abad, L.; Moratalla, J. y Tendero, M. 2000: "Contextos de Antigüedad Tardía en las termas occidentales de La Alcudia (Elche, Alicante)”. Anales de Prehistoria y Arqueología de Murcia 16: 133-147.

Abad, L. y Sala, F. (eds.) 2001: Poblamiento ibérico en el Bajo Segura. El Oral (II) y La Escuera. Bibliotheca Archaeologica Hispana 12, Real Academia de la Historia y Publicacions Universitat d'Alacant. Madrid, Alicante.

Albert-Llorca, M.; Moratalla, J. y Rouillard, P. 2018: "Le singulier destin d'une sculpture ibérique: la Dame d'Elche". Images Re-vues 15. https://doi.org/10.4000/imagesrevues.4937

Albert-Llorca, M. y Rouillard, P. 2020: La Dame d'Elche, un destin singulier. Essai sur les réceptions d'une statue ibérique. Essais 14, Casa de Velázquez. Madrid.

Aranegui Gascó, C. 2011-2012: "De nuevo Estrabón III, 4, 6-8”, Cuadernos de Prehistoria y Arqueología 37-38: 419-429.

Aranegui Gascó, C. 2018: La Dama de Elche, Dónde, cuándo y porqué. Marcial Pons Historia. Madrid.

Aranegui, C.; Jodin, A.; Llobregat, E. A.; Rouillard, P. y Uroz, J. 1993: La nécropole ibérique de Cabezo Lucero (Guardamar del Segura, Alicante). Collection de la Casa de Velázquez 41, Madrid-Alicante.

Bandera, M. L. de la y Molina, P. 2002: "Dama ibérica de Torres: una imagen de la aristocracia Oretana". Anales de Prehistoria y Arqueología 16-17: 177-188.

Bendala Galán, M. 1994: "Reflexiones sobre la Dama de Elche". Revista de Estudios Ibéricos 1: 85-105.
Bendala Galán, M. 1995: "Una nueva hipótesis sobre la dama de Elche". XXIII Congreso Nacional de Arqueología (Elche 1995): 299-304. Elche.

Bendala Galán, M. 2006: "La Dama como escultura". En S. Rovira Llorens (ed.): La Dama de Elche. Museo Arqueológico Nacional, Madrid: 49-54.

Blanco Freijeiro, A. 1960: "Die klassischen Wurzeln der iberischen Kunst”. Madrider Mitteilungen 1: 101-121.

Blanco Freijeiro, A.1987: "Las esculturas de Porcuna. I. Estatuas de guerreros". Boletín de la Real Academia de la Historia CLXXXIV: 404-445.

Blanco Freijeiro, A. 1988a: "Las esculturas de Porcuna. II. Hierofantes y cazadores". Boletín de la Real Academia de la Historia CLXXXV: $1-27$.

Blanco Freijeiro, A. 1988b: "Las esculturas de Porcuna. III. Animalia". Boletín de la Real Academia de la Historia CLXXXV: 206-234.

Blánquez, J. J. y Comas-Mata, C. 1999: "La dama sentada. Una propuesta virtual de la Dama de Elche”. En J. J. Blánquez y L. Roldán (eds.): La cultura ibérica a través de la fotografía de principios de siglo. Las colecciones madrileñas. Asistencia Técnica de Patrimonio. Madrid: 233-240.

Blánquez, J. J. y Roldán, L. 1994: "Nuevas consideraciones en torno a la historiografía y tecnología de la escultura ibérica en piedra ( $1^{\mathrm{a}}$ parte)". Revista de Estudios Ibéricos 1: 61-84.

Chapa, T. 1993: "La destrucción de la escultura funeraria ibérica". Trabajos de Prehistoria 50: 185-195. https://doi.org/10.3989/tp.1993.v50.i0.496

Chapa, T. y Belén, M. 2011: "Viaje a la eternidad. El grupo escultórico del Parque Infantil de Tráfico (Elche, Alicante)". Spal 20: 151-174. https://doi.org/10.12795/spal.2011.i20.10

Chapa, T. y González Alcalde, J. 2013: "Las esculturas ibéricas del Cerro de los Santos en la Exposición Universal de Viena (1873)". Lucentum 32: 115-130. https://doi.org/10.14198/LVCENTVM2013.32.05

Chapa, T. e Izquierdo, I. 2010 (eds.): La Dama de Baza. Un viaje femenino al más allá. Ministerio de Cultura. Madrid.

Chapa, T. y Olmos, R. 1999: "El busto de varón de Baza (Granada). Una propuesta de lectura”. En C. San Martín y M. Ramos (eds.): El guerrero de Baza. Consejería de Cultura, Junta de Andalucía. Granada: 33-40.

Chapa, T.; Vallejo, I.; Belén, M.; Martínez Navarrete, M. I.; Ceprián, B.; Rodero, A. y Pereira, J. 2009: "El trabajo de los escultores ibéricos: un ejemplo de Porcuna (Jaén)". Trabajos de Prehistoria 66 (1): 161173. https://doi.org/10.3989/tp.2009.09018

Chapa, T. y Zofío, S. 2005: "Enterrar el pasado. La destrucción del conjunto escultórico del Cerrillo Blanco de Porcuna (Jaén)". Verdolay 9: 95-120.

Cortell, E.; Juan, J.; Segura, J. M. y Trelis, J. 1989: "Dos nuevas esculturas ibéricas en la Contestania: Toro y Dama de Benimassot". En XIX Congreso Nacional de Arqueología (Castellón 1987): 543-552. Zaragoza.

Corzo Sánchez, R. 2014: "La génesis de la estatuaria ibérica". Laboratorio de Arte 26: 25-46.

Cuadrado, E. 1995: "La dama sedente de El Cigarralejo (Mula, Murcia)". En XXII Congreso Nacional de Arqueología (Vigo 1993): 247-250. Vigo.

García Gandía, J. R. 2003: "La tumba 17 de la necrópolis de Les Casetes (Villajoyosa, Alicante)". Saguntum 35: 219-228.

Guardiola Martínez, A. 2001: "La tumba: descripción y análisis". En J. L. Simón (ed.): Catálogo de la exposición 'En el umbral del Más Allá: una tumba ibérica d'Elx'. Servicios Técnicos del Ajuntament d'Elx y Pimesa: 15-28.

Gutiérrez Lloret, S. 2017: "Memorias de una Dama. La Dama de Elche como 'lugar de memoria"'. En F. J. Moreno (ed.): El franquismo y la apropiación del pasado. El uso de la Historia, de la Arqueología y de la Historia del Arte para la legitimación de la dictadura. Fundación Pablo Iglesias. Madrid: 67-92.

Ibarra Ruiz, P. 1926: Elche. Materiales para su historia. Estudio demostrativo de su antigüedad e importancia histórica. Talleres tipográficos Ruiz de Lara. Cuenca.

León, P. 1998: La sculpture des Ibères. L'Harmattan. Paris. 
Llobregat Conesa, E. A. 1972: Contestania Ibérica. Instituto de Estudios Alicantinos, Diputación Provincial de Alicante. Alicante.

Llobregat, E. A. y Jodin, A. 1990: "La Dama de Cabezo Lucero (Guardamar del Segura, Alicante)". Saguntum 23: 109-122.

Lorenzo de San Román, R. 2014: "Necròpolis romanes del camp d'Elx. Localització, descripció i cronologia”. La Rella 27: 85-127.

Luxán, M. P.; Prada, J. L.; Dorrego, F. y Dorrego, J. F. 2011: "Human bone ashes found in the Dama de Elche (V-IV century B.C.) reveal its use as an ancient cinerary urn". Journal of Cultural Heritage: 310 316. https://doi.org/10.1016/j.culher.2010.12.006

Mas Belén, B. 2017: “Un hipogeo con 'dromos' escalonado de tipología fenicio-púnica en la desembocadura del Segura”. En F. Sala y F. Prados (eds.): El oriente de occidente: fenicios y púnicos en el área ibérica. Universidad de Alicante. Alicante: 329-346.

Moratalla Jávega, J. 2004-2005: "La Alcudia ibérica: una necesaria revisión arqueológica". Lucentum XXIII-XXIV: 89-104.

Moratalla Jávega, J. 2015: "El Vuelo Ruiz de Alda (1929-30): un excepcional documento cartográfico. De nuevo sobre Ilici". Saguntum 47: 73-88.

Moratalla Jávega, J. 2016: "La ciudad ibérica". En L. Abad (ed.): L'Alcúdia d'Elx. Paseos por la historia y el entorno. L'ordit 5, Servicio de Publicaciones Universidad de Alicante. Alicante: 26-28.

Negueruela Martínez, I. 1990: Los monumentos escultóricos ibéricos del Cerrillo Blanco de Porcuna (Jaén). Ministerio de Cultura. Madrid.

Negueruela Martínez, I. 1990-1991: “Aspectos de la técnica escultórica ibérica en el siglo V a. C.”. Lucentum IX-X: 77-83.

Negueruela Martínez, I. 1992: La escultura ibérica, Cuadernos de Arte Español, 57, Madrid.

Olcina Doménech, M. 2007: "La cultura ibérica en la exposición permanente del MARQ". En L. Abad y J. Soler (eds.): Arte ibérico en la España mediterránea. Instituto "J. Gil-Albert". Alicante: 83-102.

Olmos, R. y Tortosa, T. (eds.) 1997: La Dama de Elche. Lecturas desde la diversidad. Colección Lynx 2. Madrid.

Peña Ligero, A. 2003: La necrópolis ibérica de El Molar (San FulgencioAlicante). Revisión de las excavaciones realizadas en 1928 y 1929. Fundación Municipal "José M. a Soler". Villena.

Pereira Sieso, J. 1987: "Necrópolis ibéricas de la Alta Andalucía”. En A. Ruíz y M. Molinos (eds.): Actas de las primeras jornadas sobre el mundo ibérico. Iberos. Ayuntamiento de Jaén. Jaén: 257-272.

Presedo Velo, F. J. 1973: "La Dama de Baza". Trabajos de Prehistoria 30 (1): $151-216$

Presedo Velo, F. J. 1982: La necrópolis de Baza. Excavaciones Arqueológicas en España 119, Ministerio de Cultura. Madrid.

Ramos Fernández, R. 1996-1997: “La Dama de Elche”. Arx 2-3: 139147.

Ramos Fernández, R. 2003: Documentos y reflexiones sobre una Dama. Institut Municipal de Cultura. Elx.

Ramos Fernández, R. 2008: "Sobre el vaciado dorsal de la Dama de Elche: otra observación”. Lucentum XXVII: 61-68.
Ramos Fernández, R. y Ramos Molina, A. 1992: El monumento y el témenos ibéricos del Parque de Elche. Ajuntament d'Elx. Elche.

Ramos Fernández, R. y Ramos Molina, A. 2004: "La escultura ibérica de La Alcudia". En L. Abad y M. S. Hernández (eds.): Iberia, Hispania, Spania: una mirada desde Ilici. Caja de Ahorros del Mediterráneo. Alicante: 133-144.

Ramos Folquès, A. 1944: "La Dama de Elche. Nuevas aportaciones a su estudio". Archivo Español de Arqueología 56: 253-269.

Ramos Folquès, A. 1955: Sobre escultura y cerámica ilicitanas. Estudios Ibéricos 3, Instituto de Estudios Ibéricos y Etnología Valenciana, Diputación Provincial. Valencia.

Ramos Molina, A. 2000: La escultura ibérica en el bajo Vinalopó. Institut Municipal de Cultura. Elx.

Reinach, Th. 1898: "La tête d'Elche au Musée du Louvre". Revue des Études Grecques 11 (41): 39-60.

Ronda Femenía, A. M. 2018a: "Revisión de los testimonios y documentos sobre el lugar del hallazgo de la Dama de Elche. La 'fita' de Pedro Ibarra y la recreación de Ramos Folquès". Archivo Español de Arqueología 91: 279-303. https://doi.org/10.3989/aespa.091.018.014

Ronda Femenía, A. M. 2018b: L'Alcúdia de Alejandro Ramos Folqués. Contextos arqueológicos y humanos en el yacimiento de la Dama de Elche. Publicacions Universitat d'Alacant. Alacant.

Rouillard, P. 1986: "Tombe, sculpture et durée chez les Ibères". Revue des Études Anciennes (Hommage à Robert Etienne) 88: 339-349.

Rouillard, P.; Costa, L. y Moratalla, J. (éds.) 2020:Des carrières en archipel, Au pays de la Dame d'Elche (Alicante, Espagne). Collection de la Casa de Velázquez 178, Casa de Velázquez. Madrid.

Ruano Ruiz, E. 1987: La escultura humana de piedra en el mundo ibérico. Edición de la autora. Madrid.

Ruíz Bremón, M. 1989: Los exvotos del santuario ibérico del Cerro de los Santos. Instituto de Estudios Albacetenses, Diputación de Albacete.

Ruíz Bremón, M. 1991: "La supuesta Dama sedente del Cabecico del Tesoro (Verdolay, Murcia)”. Archivo Español de Arqueología 64: 8397. https://doi.org/10.3989/aespa.1991.v64.499

Ruíz, A.; Rísquez, C. y Hornos, F. 1992: "Las necrópolis ibéricas en la Alta Andalucía”. Congreso de Arqueología Ibérica. Las Necrópolis, Universidad Autónoma de Madrid. Madrid: 397-430.

Senent Ibáñez, J. J. 1930: Memoria de las excavaciones en la necrópolis del Molar. Memorias de la Junta Superior de Excavaciones y Antigüedades 107. Madrid.

Tarradell i Mateu, M. 1968: Arte ibérico. Polígrafa. Barcelona.

Tendero, M. 2016: "Ilici. L'Alcudia d'Elx". La Rella 28: 111-142.

Tendero, M.; Ronda, A.; Ramos Fernández, R.; Ramos Molina, A.; Peña, D. y Abad, L. 2014: "Ilici”. En M. Olcina (ed.): Ciudades romanas valencianas. Museo Arqueológico de Alicante. Alacant: 223-244.

Truszkowski, E. 2003: "Réflexions sur la sculpture funéraire et votive du Sud-Est de la Péninsule Ibérique". Madrider Mitteilungen 44: 311332.

Trab. Prehist., 78, N. ${ }^{\circ} 2$, julio-diciembre 2021, pp. 366-380, ISSN: 0082-5638

https://doi.org/10.3989/tp.2021.12282 